\title{
HIMPUNAN LEMBUT KABUR INTUISIONISTIK DIPERUMUM DAN APLIKASINYA DALAM MASALAH PENGAMBILAN KEPUTUSAN DENGAN MULTI KRITERIA
}

\author{
RISCHA DEVITA \\ Program Studi Magister Matematika, \\ Fakultas Matematika dan Ilmu Pengetahuan Alam, Universitas Andalas, \\ Kampus UNAND Limau Manis Padang, Indonesia, \\ email : rischa.devita@gmail.com
}

\begin{abstract}
Abstrak. Pada tulisan ini dibahas tentang himpunan Lembut Kabur Intisionistik Diperumum (Generalized Intuitionistic Fuzzy Soft Sets) disigkat GIFSS yang merupakan perumuman dari teori himpunan Lembut Kabur Intuisionistik. Kemudian juga dibahas beberapa operasi-operasi, sifat-sifat aljabar yang berlaku, beserta contoh-contohnya. Selanjutnya juga dibahas ukuran kesamaan antara dua himpunan Lembut Kabur Intisionistik Diperumum (GIFSS) beserta sifat-sifat yang berlaku. Terakhir, dengan menggunakan pendefinisian dan sifat-sifat himpunan Lembut Kabur Intisionistik Diperumum (GIFSS) didapatkan algoritma dalam masalah pengambilan keputusan dengan multi kriteria. Sebuah contoh masalah pemilihan sebidang tanah dari beberapa alternatif dan beberapa kriteria diberikan sebagai sebuah aplikasi dari himpunan Lembut Kabur Intuisionistik Diperumum dalam masalah pengambilan keputusan dengan multi kriteria.
\end{abstract}

Kata Kunci: Himpunan Lembut, himpunan Kabur, himpunan Lembut Kabur, himpunan Lembut Kabur Intuisionistik, himpunan Lembut Kabur Intuisionistik diperumum, ukuran kesamaan, masalah pengambilan keputusan dengan multi kriteria

\section{Pendahuluan}

Dalam kehidupan sebenarnya, seringkali kita dihadapkan dengan masalah yang melibatkan ketidakpastian atau kekaburan. Seperti banyak data pada ekonomi, kesehatan, teknik, dan lain-lain yang berada pada ketidakpastian. Pada umumnya alat matematika klasik bersifat pasti dan tidak dapat digunakan untuk menyelesaikan masalah yang melibatkan ketidakpastian atau kekaburan. Oleh sebab itu, di tahun-tahun terakhir beberapa peneliti tertarik untuk menemukan suatu teori yang dapat digunakan untuk menangani masalah ketidakpastian. Seperti teori himpunan lembut yang pertama kali ditemukan oleh D. Molodtsov pada tahun 1999, himpunan kabur, himpunan kabur intisionistik, himpunan lembut kabur intisionistik, dan pengembangan-pengembangan lainnya.

Pada tulisan ini akan dibahas perumuman dari himpunan lembut kabur intuisionistik (Generalized Intuitionistic Fuzzy Soft Set) disingkat GIFSS. GIFSS merupakan pengembangan dari himpunan lembut kabur intuisionistik yang memuat derajat keanggotaan dan non-keanggotaan untuk masing-masing anggota himpunan semesta $U$ serta derajat keanggotaan dan non-keangggotaan untuk masing-masing 
anggota himpunan parameter $E$.

\section{Landasan Teori}

Pada bagian ini dibahas definisi himpunan lembut, himpunan kabur intuisionistik, dan himpunan lembut kabur intuisionistik serta operasi-operasinya.

Definisi 2.1. [2] Misalkan $U$ adalah suatu himpunan semesta, $P(U)$ adalah suatu himpunan kuasa atas $U, E$ adalah suatu himpunan parameter dan $A \subseteq E$. Maka himpunan lembut (soft set) $F_{A}$ atas $U$ adalah himpunan yang didefinisikan oleh fungsi $f_{A}$ yang dapat disajikan dalam himpunan pasangan terurut:

$$
F_{A}=\left\{\left(x, f_{A}(x)\right) \mid x \in E, f_{A}(x) \in P(U)\right\},
$$

dimana

$$
f_{A}: E \rightarrow P(U) \text { sedemikian sehingga } f_{A}(x)=\phi \text { jika } x \notin A \text {. }
$$

Definisi 2.2. [5] Misalkan U adalah himpunan semesta. Sebuah himpunan kabur intuisionistik (Intuitionistic Fuzzy Set) $X$ atas $U$ adalah himpunan yang didefinisikan oleh fungsi $\mu_{X}$ yang disajikan oleh pemetaan $\mu_{X}: U \rightarrow[0,1]$ dan fungsi $\nu_{X}$ yang disajikan oleh pemetaan $\nu_{X}: U \rightarrow[0,1]$, dengan syarat $\mu_{X}(u)+\nu_{X}(u) \leq 1$. Disini $\mu_{X}$ disebut fungsi keanggotaan atas $X$ dan $\nu_{X}$ disebut fungsi non-keanggotaan atas $X$. Himpunan kabur intuisionistik $X$ atas $U$ dapat direpresentasikan sebagai berikut.

$$
X=\left\{\left(\left(\mu_{X}(u), \nu_{X}(u)\right) / u\right) \mid u \in U, \mu_{X}(u) \in[0,1], \nu_{X}(u) \in[0,1]\right\} .
$$

Koleksi dari semua himpunan-himpunan kabur intuisionistik (Intuitionistic Fuzzy Set) atas $U$ dinotasikan dengan $\operatorname{IF} S(U)$.

Definisi 2.3. [5] Misalkan $A$ dan $B$ adalah dua IFS atas himpunan semesta $U$, maka:

(a) $A \subset B$ jika $\mu_{A}(x) \leq \mu_{B}(x)$ dan $\nu_{A}(x) \geq \nu_{B}(x)$ untuk setiap $x \in U$,

(b) $A^{c}=\left\{\left(x, \nu_{A}(x), \mu_{A}(x)\right) \mid x \in U\right\}$.

Definisi 2.4. [6] Misalkan $U$ adalah suatu himpunan semesta, E adalah suatu himpunan parameter, $A \subseteq E$ dan $\gamma_{A}(x)$ adalah himpunan kabur intuisionistik atas $U$ untuk semua $x \in A$. Maka himpunan lembut kabur intuisionistik (Intuitionistic fuzzy soft set atau disingkat IFSS) $\Gamma_{A}$ atas $U$ adalah himpunan yang didefinisikan oleh fungsi $\gamma_{A}$ yang disajikan dalam bentuk himpunan pasangan terurut:

$$
\Gamma_{A}=\left\{\left(x, \gamma_{A}(x)\right) \mid x \in A, \gamma_{A}(x) \in \operatorname{IFS}(U)\right\},
$$

dengan

$$
\gamma_{A}: A \rightarrow I F S(U)
$$

Definisi 2.5. [3] Suatu IFS juga dapat ditulis sebagai suatu himpunan L-Fuzzy $\left(L_{*}\right)$ yang didefinisikan sebagai berikut.

$$
L_{*}=\left\{\left(x_{1}, x_{2}\right) \mid x_{1}, x_{2} \in[0,1] ; x_{1}+x_{2} \leq 1\right\} .
$$


Definisi 2.6. [3] Operator $\wedge$ dan $\vee \operatorname{pada}\left(L_{*}, \leq_{L_{*}}\right)$ didefinisikan sebagai berikut.

$$
\begin{aligned}
& \left(x_{1}, x_{2}\right) \wedge\left(y_{1}, y_{2}\right)=\left(\min \left\{x_{1}, y_{1}\right\}, \quad \max \left\{x_{2}, y_{2}\right\}\right), \\
& \left(x_{1}, x_{2}\right) \vee\left(y_{1}, y_{2}\right)=\left(\max \left\{x_{1}, y_{1}\right\}, \min \left\{x_{2}, y_{2}\right\}\right),
\end{aligned}
$$

untuk setiap $\left(x_{1}, x_{2}\right) ;\left(y_{1}, y_{2}\right) \in L_{*}$.

Definisi 2.7. [3] Suatu $t$-norm $t$ dan $t$-conorm $s$ adalah suatu operasi biner $[0,1] \times[0,1] \rightarrow[0,1]$ dan memenuhi kondisi berikut.

(i) Komutatif, yaitu $t(a, b)=t(b, a)$ dan $s(a, b)=s(b, a) \forall a, b \in[0,1]$,

(ii) Assosiatif, yaitu $t(a, t(b, c))=t(t(a, b), c), s(a, s(b, c))=s(s(a, b), c)$,

(iii) $t(a, 1)=a, s(a, 0)=0 \forall a \in[0,1]$,

(iv) $t(a, b) \leq t(c, d), s(a, b) \leq s(c, d)$ dimana $a \leq c, b \leq d$ dan $a, b, c, d \in[0,1]$.

\section{Himpunan Lembut Kabur Intuisionistik Diperumum dan Sifat-Sifatnya}

Pada bagian ini akan dibahas suatu definisi perumuman dari himpunan lembut kabur intuisionistik dan beberaa sifat-sifatnya.

Definisi 3.1. [1] Misalkan $U=\left\{x_{1}, x_{2}, \cdots, x_{n}\right\}$ himpunan semesta dan E himpunan parameter. Pasangan $(U, E)$ disebut semesta lembut. Misalkan $F: E \rightarrow$ $\operatorname{IFS}(U)$ dan $\langle\mu, \nu\rangle$ himpunan kabur intuisionistik atas $E$, yaitu $\mu, \nu: E \rightarrow[0,1]$, dimana IFS $(U)$ adalah himpunan kabur intuisionistik atas $U$. Misalkan $F_{\mu \nu}: E \rightarrow$ $I F S(U) \times I^{2}$ didefinisikan sebagai berikut.

$$
F_{\mu \nu}=\{(F(e),\langle\mu(e), \nu(e)\rangle)\},
$$

dimana $F(e) \in I F S(U)$. Maka $F_{\mu \nu}$ disebut himpunan lembut kabur intuisionistik diperumum (GIFSS) atas semesta lembut $(U, E)$.

Contoh 3.2. Misalkan $U$ himpunan obat-obat yang diberikan oleh $U=$ $\left\{m_{1}, m_{2}, m_{3}\right\}$ dan $E=\left\{e_{1}, e_{2}, e_{3}\right\}$ dimana $e_{1}$ malaria, $e_{2}$ thypoid, dan $e_{3}$ sakit kepala. Misalkan $\langle\mu, \nu\rangle$ adalah himpunan kabur intuisionistik atas $E$ yang didefinisikan sebagai berikut.

$$
\begin{aligned}
& \mu\left(e_{1}\right)=0.1, \mu\left(e_{2}\right)=0.6, \mu\left(e_{3}\right)=0.8 . \\
& \nu\left(e_{1}\right)=0.8, \nu\left(e_{2}\right)=0.3, \nu\left(e_{3}\right)=0.2 .
\end{aligned}
$$

Didefinisikan suatu fungsi $F_{\mu \nu}: E \rightarrow I F S(U) \times I^{2}$ sebagai berikut.

$$
\begin{aligned}
& F_{\mu \nu}\left(e_{1}\right)=\left\{\left(\frac{m_{1}}{(0.7,0.2)}, \frac{m_{2}}{(0.4,0.3)}, \frac{m_{3}}{(0.3,0.5)},\langle 0.1,0.8\rangle\right)\right\}, \\
& F_{\mu \nu}\left(e_{2}\right)=\left\{\left(\frac{m_{1}}{(0.1,0.8)}, \frac{m_{2}}{(0.2,0.7)}, \frac{m_{3}}{(0.9,0.1)},\langle 0.6,0.3\rangle\right)\right\}, \\
& F_{\mu \nu}\left(e_{3}\right)=\left\{\left(\frac{m_{1}}{(0.8,0.1)}, \frac{m_{2}}{(0.5,0.5)}, \frac{m_{3}}{(0.2,0.7)},\langle 0.8,0.2\rangle\right)\right\} .
\end{aligned}
$$

GIFSS yang dibahas di atas dapat direpresentasikan dalam bentuk Tabel 1: 
Tabel 1. $F_{\mu \nu}$

\begin{tabular}{|c|c|c|c|}
\hline & $e_{1}$ & $e_{2}$ & $e_{3}$ \\
\hline$m_{1}$ & $(0.7,0.2)$ & $(0.1,0.8)$ & $(0.8,0.1)$ \\
\hline$m_{2}$ & $(0.4,0.3)$ & $(0.2,0.7)$ & $(0.5,0.5)$ \\
\hline$m_{3}$ & $(0.3,0.5)$ & $(0.9,0.1)$ & $(0.2,0.7)$ \\
\hline$\langle\mu, \nu\rangle$ & $\langle 0.1,0.8\rangle$ & $\langle 0.6,0.3\rangle$ & $\langle 0.8,0.2\rangle$ \\
\hline
\end{tabular}

Definisi 3.3. [1] Misalkan $F_{\mu \nu}$ dan $G_{\alpha \beta}$ adalah GIFSS atas $(U, E)$. Maka $F_{\mu \nu}$ dikatakan subhimpunan lembut kabur intuisionistik diperumum dari $G_{\alpha \beta}$ dan dinotasikan dengan $F_{\mu \nu} \widetilde{\subseteq} G_{\alpha \beta}$ jika:

(a) $\langle\mu, \nu\rangle$ adalah subhimpunan kabur intuisionistik dari $\langle\alpha, \beta\rangle$.

(b) $F(e)$ subhimpunan kabur intuisionistik dari $G(e)$ untuk setiap $e \in E$.

Definisi 3.4. [1] Diberikan suatu $t$-norm $t$ dan $t$-conorm s yang memenuhi $t(a, b) \leq$ $1-s(1-a, 1-b)$ untuk setiap $a, b \in[0,1]$. Selanjutnya didefinisikan pemetaan $T$ dan $S$ sebagai berikut.

$$
\begin{aligned}
& T(x, y)=\left(t\left(x_{1}, y_{1}\right), s\left(x_{2}, y_{2}\right)\right), \\
& S(x, y)=\left(s\left(x_{1}, y_{1}\right), t\left(x_{2}, y_{2}\right)\right),
\end{aligned}
$$

untuk setiap $x=\left(x_{1}, x_{2}\right)$ dan $y=\left(y_{1}, y_{2}\right) \in[0,1] \times[0,1]$. $T$ dan $S$ yang demikian berturut-turut disebut IF t-norm dan IF t-conorm.

Definisi 3.5. [1] Jika $n$ adalah negator kabur involutive dan $N$ adalah suatu negator kabur intuisionistik dengan definisi $N(x)=\left(n\left(1-x_{2}\right), 1-n\left(x_{1}\right)\right)$ maka $N$ disebut negator kabur intuisionistik involutive.

Definisi 3.6. [1] Misalkan $F_{\mu \nu}$ dan $G_{\alpha \beta}$ GIFSS atas U, E. Maka:

(a) $\left(F_{\mu \nu}\right)^{c}=H_{\gamma \delta}=\{(H(e),\langle\gamma(e), \delta(e)\rangle)\}$ dengan $H(e)=N(F(e))$ dan $\langle\gamma(e), \delta(e)\rangle=N(\langle\mu(e), \nu(e)\rangle,\langle\mu(e), \nu(e)\rangle)$,

(b) $F_{\mu \nu} \widetilde{\cup} G_{\alpha \beta}=H_{\eta \theta}=\{(H(e),\langle\eta(e), \theta(e)\rangle)\}$ dengan $H(e)=S(F(e), G(e))$ dan $\langle\eta(e), \theta(e)\rangle=S(\langle\mu, \nu\rangle,\langle\alpha, \beta\rangle)$,

(c) $F_{\mu \nu} \widetilde{\cap} G_{\alpha \beta}=H_{\xi \omega}=\{(H(e),\langle\xi(e), \omega(e)\rangle)\}$ dengan $H(e)=T(F(e), G(e))$ $\operatorname{dan}\langle\xi(e), \omega(e)\rangle=T(\langle\mu, \nu\rangle,\langle\alpha, \beta\rangle)$.

Definisi 3.7. [1] Suatu GIFSS dikatakan himpunan lembut kabur intuisionistik absolut diperumum yang dinotasikan sebagai $A_{\alpha_{1} \alpha_{2}}$ jika $A_{\alpha_{1} \alpha_{2}}(e)=$ $\left\{\left(A(e),\left\langle\alpha_{1}(e), \alpha_{2}(e)\right\rangle\right)\right\}$ dimana $A(e)$ adalah absolut himpunan lembut kabur intuisionistik, $\alpha_{1}(e)=1, \alpha_{2}(e)=0$ untuk setiap $e \in E$.

Definisi 3.8. [1] Suatu GIFSS dikatakan null himpunan lembut kabur intuisionistik diperumum yang dinotasikan sebagai $\phi_{\theta_{1} \theta_{2}}$ jika $\phi_{\theta_{1} \theta_{2}}(e)=\left\{\left(\phi(e),\left\langle\theta_{1}(e), \theta_{2}(e)\right\rangle\right)\right\}$ dimana $\phi(e)$ adalah null himpunan lembut kabur intuisionistik, $\theta_{1}(e)=0, \theta_{2}(e)=1$ untuk setiap $e \in E$.

Proposisi 3.9. [1] Misalkan $F_{\mu \nu}$ adalah $\operatorname{GIFSS}$ atas $(U, E)$ maka:

(i) $F_{\mu \nu} \widetilde{\subseteq}\left(F_{\mu \nu} \widetilde{\cup} F_{\mu \nu}\right)$. 
(ii) $\left(F_{\mu \nu} \widetilde{\cap} F_{\mu \nu}\right) \widetilde{\widetilde{\subseteq}} F_{\mu \nu}$.

(iii) $F_{\mu \nu} \widetilde{\cup} \phi_{\theta_{1} \theta_{2}}=F_{\mu \nu}$.

(iv) $F_{\mu \nu} \widetilde{\cap} A_{\alpha_{1} \alpha_{2}}=F_{\mu \nu}$.

Bukti. Bukti dapat dilakukan dengan menggunakan Definisi 3.3, Definisi 3.6, Definisi 3.7 dan Definisi 3.8.

Proposisi 3.10. [1] Misalkan $F_{\mu \nu}, G_{\alpha \beta}$, dan $H_{\gamma \delta}$ adalah $\operatorname{GIFSS}$ atas $(U, E)$ maka:

(i) $F_{\mu \nu} \widetilde{\cup} G_{\alpha \beta}=G_{\alpha \beta} \widetilde{\cup} F_{\mu \nu}$.

(ii) $F_{\mu \nu} \widetilde{\cap} G_{\alpha \beta}=G_{\alpha \beta} \widetilde{\cap} F_{\mu \nu}$

(iii) $F_{\mu \nu} \widetilde{\cup}\left(G_{\alpha \beta} \widetilde{\cup} H_{\gamma \delta}\right)=\left(F_{\mu \nu} \widetilde{\cup} G_{\alpha \beta}\right) \widetilde{\cup} H_{\gamma \delta}$.

(iv) $F_{\mu \nu} \widetilde{\cap}\left(G_{\alpha \beta} \widetilde{\cap} H_{\gamma \delta}\right)=\left(F_{\mu \nu} \widetilde{\cap} G_{\alpha \beta}\right) \widetilde{\cap} H_{\gamma \delta}$.

Bukti. Bukti dapat dilakukan dengan menggunakan Definisi 3.6, Definisi 3.7 dan Definisi 3.8.

Proposisi 3.11. [1] Misalkan $F_{\mu \nu}$ dan $G_{\alpha \beta}$, adalah GIFSS atas $(U, E)$. Misalkan didefinisikan suatu negator kabur intuisionistik involutive $N$, dengan $N\left(x_{1}, x_{2}\right)=$ $\left(x_{2}, x_{1}\right)$ untuk setiap $\left(x_{1}, x_{2}\right) \in[0,1] \times[0,1]$ maka:

(i) $\left(F_{\mu \nu} \widetilde{\cup} G_{\alpha \beta}\right)^{c}=\left(F_{\mu \nu}\right)^{c} \widetilde{\cap}\left(G_{\alpha \beta}\right)^{c}$,

(ii) $\left(F_{\mu \nu} \widetilde{\cap} G_{\alpha \beta}\right)^{c}=\left(F_{\mu \nu}\right)^{c} \widetilde{\cup}\left(G_{\alpha \beta}\right)^{c}$,

(iii) $F_{\mu \nu} \widetilde{\cup}\left(F_{\mu \nu}\right)^{c} \neq A_{\alpha_{1} \alpha_{2}}$,

(iv) $F_{\mu \nu} \widetilde{\cap}\left(F_{\mu \nu}\right)^{c} \neq \phi_{\theta_{1} \theta_{2}}$.

Bukti. Bukti dapat dilakukan dengan menggunakan Definisi 3.6, Definisi 3.7 dan Definisi 3.8.

\section{Ukuran Kesamaan Dua Himpunan Lembut Kabur Intuisionistik Diperumum}

Pada bagian ini akan dibahas suatu ukuran kesamaan antara dua GIFSS dan beberapa sifat yang dihasilkan.

Definisi 4.1. [8] Untuk sebarang dua himpunan kabur intuisionistik $A$ dan $B$, ukuran kesamaan $K(A, B)$ antara $A$ dan $B$ didefinisikan sebagai

$$
K(A, B)=\frac{\sum_{y} A_{y} \cdot B_{y}}{\max \left\{\sum_{y}\left(A_{y}\right)^{2}, \sum_{y}\left(B_{y}\right)^{2}\right\}},
$$

dimana

$$
\begin{aligned}
A_{x} & =\left(\mu_{A}(x), \nu_{A}(x), \pi_{A}(x)\right), \\
B_{x} & =\left(\mu_{B}(x), \nu_{B}(x), \pi_{B}(x)\right), \\
\pi_{A}(x) & =1-\mu_{A}(x)-\nu_{A}(x) .
\end{aligned}
$$

Definisi 4.2. [1] Misalkan $U=\left\{x_{1}, x_{2}, \cdots, x_{n}\right\}$ adalah himpunan semesta dan misalkan $E=\left\{e_{1}, e_{2}, \cdots, e_{n}\right\}$ adalah himpunan parameter. Misalkan $F_{\gamma \delta}$ dan 
$G_{\alpha \beta}$ adalah himpunan lembut kabur intuisionistik diperumum (GIFSS) atas $(U, E)$. Misalkan $\widehat{F}=\left\{F\left(e_{i}\right) ; i=1,2, \cdots, m\right\}$ dan $\widehat{G}=\left\{G\left(e_{i}\right) ; i=1,2, \cdots, m\right\}$ adalah himpunan lembut kabur intuisionistik. Misalkan $K_{i}\left(F\left(e_{i}\right), G\left(e_{i}\right)\right)$ menotasikan ukuran kesamaan antara himpunan kabur intuisionistik (IFS) $F\left(e_{i}\right)$ dan $G\left(e_{i}\right)$, dan $K(\langle\gamma, \delta\rangle,\langle\alpha, \beta\rangle)$ menotasikan ukuran kesamaan antara himpunan kabur intuisionistik (IFS) $\langle\gamma, \delta\rangle$ dan $\langle\alpha, \beta\rangle$. Maka ukuran kesamaan antara dua GIFSS $F_{\gamma \delta}$ dan $G_{\alpha \beta}$ diberikan oleh

$$
K\left(F_{(\gamma \delta)}, G_{(\alpha \beta)}\right)=K(\widehat{F}, \widehat{G}) \cdot K(\langle\gamma, \delta\rangle,\langle\alpha, \beta\rangle),
$$

$\operatorname{dimana} K(\widehat{F}, \widehat{G})=\max _{i} K_{i}\left(F\left(e_{i}\right), G\left(e_{i}\right)\right)$.

Proposisi 4.3. [1] Misalkan $F_{\gamma \delta}$ dan $G_{\alpha \beta}$ adalah dua GIFSS atas (U, E). Maka berlaku:

(i) $K\left(F_{\gamma \delta}, G_{\alpha \beta}\right)=K\left(G_{\alpha \beta}, F_{\gamma \delta}\right)$.

(ii) $0 \leq K\left(F_{\gamma \delta}, G_{\alpha \beta}\right) \leq 1$.

(iii) $K\left(F_{\gamma \delta}, F_{\gamma \delta}\right)=1$.

Bukti. Bukti dapat dilakukan dengan menggunakan Definisi 4.2.

Definisi 4.4. [1] Relasi $\sim^{\epsilon}$ pada GIFSS $(U)$ disebut similar $\epsilon$. Dua GIFSS $F_{\gamma \delta}$ dan $G_{\alpha \beta}$ dikatakan similar $\epsilon$ dinotasikan $F_{\gamma \delta} \sim^{\epsilon} G_{\alpha \beta}$ jika $K\left(F_{\gamma \delta}, G_{\alpha \beta}\right) \geq \epsilon$ untuk setiap $\epsilon \in[0,1]$. Dua GIFSS dikatakan similar signifikan jika $K\left(F_{\gamma \delta}, G_{\alpha \beta}\right)>\frac{1}{2}$.

Proposisi 4.5. [1] Relasi $\sim^{\epsilon}$ bersifat refleksif, simetris, tetapi tidak transitif.

Bukti. Bukti dapat dilakukan dengan menggunakan Definisi 4.2, Definisi 4.4 dan Proposisi 4.3.

\section{Aplikasi GIFSS dalam Masalah Pengambilan Keputusan dengan Multi Kriteria}

Pada bagian ini akan dibahas suatu aplikasi GIFSS dalam masalah pengambilan keputusan dengan multi kriteria. Kemudian, dibahas satu contoh pengambilan keputusan berdasarkan algoritma yang diberikan oleh H.W Liu [4].

Definisi 5.1. [1] Misalkan $M=\left\{M_{1}, M_{2}, M_{3}, \cdots, M_{m}\right\}$ adalah himpunan alternatif dan $C=\left\{c_{1}, c_{2}, \cdots, c_{n}\right\}$ adalah himpunan kriteria. Asumsikan bahwa karakteristik dari $M_{i}$ dinyatakan sebagai suatu GIFSS sebagai berikut.

$$
\left\{\left(c_{1}, F\left(c_{1}\right), \alpha\left(c_{1}\right), \beta\left(c_{1}\right)\right), \cdots,\left(c_{n}, F\left(c_{n}\right), \alpha\left(c_{n}\right), \beta\left(c_{n}\right)\right)\right\},
$$

dimana $F\left(c_{j}\right)=\left\{\left(\mu_{i j}, \nu_{i j}\right) \mid i=1,2, \cdots, m, j=1,2, \cdots, n\right\}, \mu_{i j}$ adalah derajat $M_{i}$ yang memenuhi kriteria $c_{j}$ dan $\beta_{i j}$ adalah derajat $M_{i}$ yang tidak memenuhi kriteria $c_{j}$. Kemudian $\alpha\left(c_{j}\right)$ adalah derajat kemungkinan ketermasukan $F\left(c_{j}\right)$ dan $\beta\left(c_{j}\right)$ menotasikan derajat ketidakmungkinan ketermasukan $F\left(c_{j}\right)$. Disini, catat bahwa $\left(\mu_{i j}, \nu_{i j}\right)$ dan $\left\langle\alpha\left(c_{j}\right), \beta\left(c_{j}\right)\right\rangle \in L_{*}$. Asumsikan bahwa terdapat seorang pengambil keputusan yang ingin memilih suatu alternatif $M_{i}$ yang memenuhi kriteria

$$
c_{j} \text { dan } c_{k} \cdots \text { dan } c_{p} \text { atau } c_{s} \text {. }
$$


Definisi 5.2. [1] Didefinisikan nilai evaluasi untuk alternatif $M_{i}$ yang memenuhi persyaratan dari pengambil keputusan pada pernyataan (5.1) sebagai berikut.

$$
\begin{aligned}
E_{v}\left(M_{i}\right) & =S\left(T_{j, k, \cdots, p}\left(\mu_{i q}, \nu_{i q}\right),\left(\mu_{s q}, \nu_{s q}\right)\right) \\
& =E_{v}\left(M_{i}\right)=\left(\mu_{M_{i}}, \nu_{M_{i}}\right)
\end{aligned}
$$

dimana $T$ adalah IF t-norm dan $S$ adalah IF $t$-conorm pada $L_{*}$.

Definisi 5.3. [1] Nilai Evaluasi untuk himpunan kabur intuisionistik (IFS) $\langle\alpha, \beta\rangle$ dinyatakan sebagai berikut.

$$
E_{v}\langle\alpha, \beta\rangle=\left(\alpha_{c_{d}}, \beta_{c_{d}}\right) .
$$

Definisi 5.4. [1] Derajat kelayakan untuk alternatif yang memenuhi persyaratan dari pengambil keputusan dapat diukur dengan fungsi skor $J_{n}$ (untuk sebarang bilangan bulat) atau $J_{\infty}$ sebagai berikut.

$$
\begin{aligned}
J_{n} E_{v}\left(M_{i}\right)= & \mu_{M_{i}}+\alpha_{c_{d}} \pi_{E_{v}\left(M_{i}\right)}+\alpha_{c_{d}}\left(1-\alpha_{c_{d}}-\beta_{c_{d}}\right) \pi_{E_{v}\left(M_{i}\right)}+\cdots+ \\
& \alpha_{c_{d}}\left(1-\alpha_{c_{d}}-\beta_{c_{d}}\right)^{n-1} \pi_{E_{v}\left(M_{i}\right)} . \\
J_{\infty} E_{v}\left(M_{i}\right)= & \mu_{M_{i}}+\frac{\alpha_{c_{d}}}{\alpha_{c_{d}}+\beta_{c_{d}}} \pi_{E_{v}\left(M_{i}\right)} .
\end{aligned}
$$

\section{Langkah-langkah Pengambilan Keputusan dengan Multi Kriteria pada GIFSS}

(1) Hitung nilai evaluasi $E_{v}$ untuk alternatif $M_{i}$ dan himpunan kabur intuisionistik $\langle\alpha, \beta\rangle$.

(2) Cari derajat kelayakan $J_{n}$ untuk alternatif $M_{i},(i=1,2, \cdots, m)$ yang memenuhi persyaratan dari pengambil keputusan.

(3) Jika terdapat $i_{0} \in\{1,2, \cdots, m\}$ sedemikian sehingga $J_{n}\left(E_{v}\left(M_{i_{0}}\right)\right)$ adalah nilai terbesar di antara nilai-nilai $J_{n}\left(E_{v}\left(M_{i}\right)\right),(i=1,2, \cdots, m)$ maka alternatif $M_{i_{0}}$ adalah nilai terbaik.

Contoh 5.5. Perhatikan masalah pemilihan sebidang tanah berikut. Misalkan terdapat 3 bidang tanah yang dinyatakan sebagai himpunan alternatif $\left\{p_{1}, p_{2}, p_{3}\right\}$. Misalkan terdapat tiga kriteria yaitu $c_{1}$ (hijau), $c_{2}$ (murah), $c_{3}$ (disamping bukit) yang akan dipertimbangkan dalam masalah ini. Pengambil keputusan ingin memilih sebidang tanah yang bergantung pada kriteria $c_{1}, c_{2}$ atau $c_{3}$. Misalkan dilakukan pengamatan yang dinyatakan pada Tabel 2.

Tabel 2 .

\begin{tabular}{|c|c|c|c|}
\hline & $c_{1}$ & $c_{2}$ & $c_{3}$ \\
\hline$p_{1}$ & $(0.2,0.2)$ & $(0.3,0.1)$ & $(0.2,0.0)$ \\
\hline$p_{2}$ & $(0.3,0.3)$ & $(0.2,0.2)$ & $(0.3,0.1)$ \\
\hline$p_{3}$ & $(0.4,0.4)$ & $(0.5,0.4)$ & $(0.3,0.2)$ \\
\hline$\langle\mu, \nu\rangle$ & $\langle 0.4,0.4\rangle$ & $\langle 0.6,0.3\rangle$ & $\langle 0.6,0.4\rangle$ \\
\hline
\end{tabular}

Ambil IF t-norm $T=\wedge$ dan IF t-conorm $S=\vee$. Diperoleh nilai-nilai evaluasi untuk $p_{1}, p_{2}, p_{3}$ dan $\langle\alpha, \beta\rangle$ sebagai berikut.

$$
E_{v}\left(p_{1}\right)=(0.2,0), E_{v}\left(p_{2}\right)=(0.3,0.1), E_{v}\left(p_{3}\right)=(0.4,0.2), E_{v}\langle\alpha, \beta\rangle=(0.5,0.3) .
$$


Kemudian diproleh nilai fungsi skor untuk beberapa nilai $n$ yang disajikan dalam Tabel 3.

Tabel 3.

\begin{tabular}{|c|c|c|c|}
\hline & $J_{n}\left(E_{v}\left(p_{1}\right)\right)$ & $J_{n}\left(E_{v}\left(p_{2}\right)\right)$ & $J_{n}\left(E_{v}\left(p_{3}\right)\right)$ \\
\hline$n=1$ & 0.6 & 0.6 & 0.6 \\
\hline$n=2$ & 0.68 & 0.66 & 0.64 \\
\hline$n=3$ & 0.696 & 0.672 & 0.648 \\
\hline$n=4$ & 0.6992 & 0.6744 & 0.6496 \\
\hline$n=5$ & 0.69984 & 0.67788 & 0.64992 \\
\hline$n \rightarrow \infty$ & 0.7 & 0.675 & 0.65 \\
\hline
\end{tabular}

Berdasarkan Tabel 3 dapat disimpulkan bahwa pilihan terbaik adalah alternatif $p_{1}$.

\section{Kesimpulan}

Himpunan lembut kabur intuisionistik diperumum GIFSS merupakan suatu perumuman dari himpunan lembut kabur intuisionistik yang memuat derajat keanggotaan dan non-keanggotaan dari masing-masing elemen di himpunan $U$ dan himpunan $E$. Selain sifat-sifat aljabarnya, juga dapat dihitung ukuran kesamaan dari dua $G I F S S$ dan aplikasinya dalam masalah pengambilan keputusan. Dalam tulisan ini dibahas mengenai pemilihan sebidang tanah dari beberapa alternatif dan kriteria.

\section{Daftar Pustaka}

[1] Babhita K. V dan Sunil Jacob John. 2011. Generalized Intuitionistic Fuzzy Soft Sets and Its Applications. Information and Control $8: 338-353$

[2] D. Molodtsov. 1999. Soft Set Theory-first Result. Comput. Math. Appl. 37 : 19 $-31$

[3] Glad Deschrijver, C. Kornelis, dan E. Kerre. 2004. On the representation of intuitionistic fuzzy t-norms and t-conorms. IEEE transactions on Fuzzy Systems $8: 338-353$

[4] Hua-Wen Liu dan Guo-jun Wang. 2007.Multi-criteria Decision-Making methods Based on Intuitionistic Fuzzy Sets. European Journal of Operational Research 179 (1) : $220-223$

[5] K.T. Atanassov. 1986. Intuitionistic Fuzzy Sets. Fuzzy Sets and Systems 20 : $87-96$

[6] L.A. Zadeh. 1965. Fuzzy Sets. Information and Control. 8 : $338-353$

[7] P.K. Maji, R. Biswas, dan A.R. Roy. 2001. Intuitionistic Fuzzy Soft Sets. The Journal of Fuzzy Mathematics 9 (3) : 677 - 693

[8] P.K. Maji, R. Biswas, dan A.R. Roy. 2004. On Intuitionistic Fuzzy Soft Sets. The Journal of Mathematics 12 (3) : 669 - 683 